\title{
OPTIMISATION OF A MICROELECTRONIC ASSEMBLY PACKAGE USING RESPONSE SURFACE METHODOLOGY
}

\author{
M. Ekpu* \\ Dept of Mechanical Engineering, Delta State Univ. Abraka, Oleh Campus, Delta State, nigeria \\ E-mail address: ekpum@delsu.edu.ng
}

\begin{abstract}
This article addressed heat conduction in microelectronics applications. ANSYS finite element design software was used to design the model, while Design Expert software was used for the response surface methodology (RSM) analysis. The components analysed were heat-sink base (HSB) thickness, thermal interface material (TIM) thickness, and chip thickness. A design of experiment comprising of 15 central composite design (CCD) for the coded levels (low (-) and high $(+))$ of the factors were generated. Heat flow was applied to the chip while a convective coefficient was applied to the heat-sink. The temperature solution was used to calculate the thermal resistance response for the 15 CCD experimental runs. The results from the RSM study proposed an optimal (minimization analysis) combination of $3.5 \mathrm{~mm}, 0.04 \mathrm{~mm}$, and $0.75 \mathrm{~mm}$, for HSB thickness, TIM thickness, and chip thickness respectively. While the optimal mean thermal resistance of $0.31052 \mathrm{~K} / \mathrm{W}$ was achieved from the proposed optimal parameters.
\end{abstract}

Keywords: RSM; CCD; thermal resistance; temperature; microelectronics

\section{INTRODUCTION}

Heat management in microelectronics devices remain a challenge despite increased attention given to it. Most research works on managing heat in microelectronic devices centred their research on heat sink [1-4]. However, understanding how heat is conducted and managed in electronic packages are vital in the development of the components used in the assembly process. One of the ways to effectively dissipate heat from an electronic device is to ensure that the components used in the assembly process are of the right specification and quality. This could be achieved by making sure that the components used are optimised based on engineering specifications. There are different ways of optimising design specifications, but a lot of researchers [5 -8$]$ have used response surface methodology (RSM) and other optimisation methods to optimise components of different applications.

Oghenejoboh [9] used response surface methodology approach to analyse the Biosorption of nickel (II) ion from synthetic wastewater on watermelon rind activated carbon. The research established that response surface methodology is a vital tool for saving cost in the optimisation of adsorption process parameters. In another study by Leong et a/[10], response surface methodology was used in the optimisation of flexible printed circuit board of electronics in the flow environment. The authors developed an empirical model using response surface methodology. The empirical model was used to optimise the process parameters which resulted in a maximum deflection and maximum stress of $0.402 \mathrm{~mm}$ and $0.582 \mathrm{MPa}$ respectively.

Wang et al [11], did a study on a novel response surface method for design optimization of electronic packages. The research was based upon the fact that if too few sampling points or too many sampling points are used in RSM, it may lead to inaccurate results or expensive process respectively. The authors stated that RSM could be improved by their proposed sequential response surface refinement scheme couple Quasi-Monte Carlo sampling method. Gaston and Walton [12] researched on integrating simulation with response surface methodology in the optimisation of integrated circuit (IC) processes. The

*Author, tel: +234 - $905-164-7034$ 
authors inferred that the combination of RSM and simulation is an extremely powerful concept in optimisation analysis and that it could be readily implemented by using available design of experiment (DOE) software.

In this study, response surface methodology (RSM) is employed for the optimisation of the required response $[13,14]$. The second-order approximation function is used to describe the formulation of a response surface, and is represented mathematically as:

$F(x)=a_{o}+\sum_{i=1}^{n_{d v}} b_{i} x_{i}+\sum_{i=1}^{n_{d v}} c_{i i} x_{i}^{2}+\sum_{i j(i<j)}^{n_{d v}} c_{i j} x_{i} x_{j}(1)$ Where $F(x)$ is the function or response approximated, $x_{1}\left(i=1, n_{d v}\right)$ are the $n_{d v}$ design variables, and $\left(a_{0}, b_{i}, c_{i i}, c_{i j}\right)$ are the least-square fit coefficients [13].

Also, other researchers have conducted investigations on optimization of different parameters that could enhance thermal management in different applications $[14,15]$. This investigation is aimed at proposing an optimal thermal resistance based on heat sink base (HSB) thickness, TIM thickness, and chip thickness.

\section{MATERIALS AND METHOD}

\subsection{Experimental Design and Model Description}

The components considered in this work are heat sink, thermal interface material (TIM), and flip chip. The three components are vital in heat generation and dissipation. In terms of assembling the components, the chip is mounted on the circuit board, while TIM is applied before mounting the heat sink. The chip is the heat generating device while the generated heat is dissipated through the TIM and heat sink to the environment. To effectively manage the thermal processes in the electronic package, it is necessary to have the right size of the components. To achieve the right size of components, it is advisable to employ optimisation.

This research work employs ANSYS for the development of the microelectronic assembly package (MAP). The initial dimensions of the developed model are given as: $10 \mathrm{~mm} \times 10 \mathrm{~mm} \times$ $0.5 \mathrm{~mm}$ for the chip, $10 \mathrm{~mm} \times 10 \mathrm{~mm} \times 0.035 \mathrm{~mm}$ for the TIM, and $30 \mathrm{~mm} \times 30 \mathrm{~mm} \times 2 \mathrm{~mm}$ for the heat sink base (HSB). In addition, there were ten (10) rectangular fins, each measuring $10 \mathrm{~mm}$ height, $30 \mathrm{~mm}$ length, and $1.5 \mathrm{~mm}$ width respectively.
Figure 1 presents a schematic of the designed microelectronic assembly package.

In order to develop the design of experiment for the simulation runs, the Design Expert software was utilised. Montgomery [16] explained in detail the concept of design of experiment. In the present study, three factors were considered HSB thickness, TIM thickness, and flip chip thickness. The Design Expert coded levels of low (-) and high (+) were employed in the determination of the factors levels used in this investigation. Table 1 presents the MAP factors and its corresponding levels. The tolerance for the HSB thickness, TIM thickness, and chip thickness are $\pm 1, \pm 0.002$, and \pm 0.104 respectively. After running the central composite design (CCD), a fifteen (15) run order were generated for the factors and levels as seen in Table 2. The response for the simulation design is thermal resistance in $\mathrm{K} / \mathrm{W}$. Thermal resistance is chosen as the response for this study because it is a vital parameter in the effective conduction of heat in microelectronics packages.

\subsection{Materials}

The materials used in this work are aluminium, silicon, and lead-free solder (SAC405 having a composition of Sn95.5Ag4.0Cu0.5). SAC405 is used as the material for the TIM because Ekpu et al [17] suggested in their work, that SAC405 is a better TIM compared to SAC105 and SAC305. The heat sink is aluminium, the chip is silicon, and the TIM is SAC405. The thermal conductivity of the materials as reported by Ekpu et al [18] were $237.5 \mathrm{~W} / \mathrm{mK}$, $148 \mathrm{~W} / \mathrm{mK}$, and $62 \mathrm{~W} / \mathrm{mK}$ for aluminium, silicon, and SAC405 respectively.

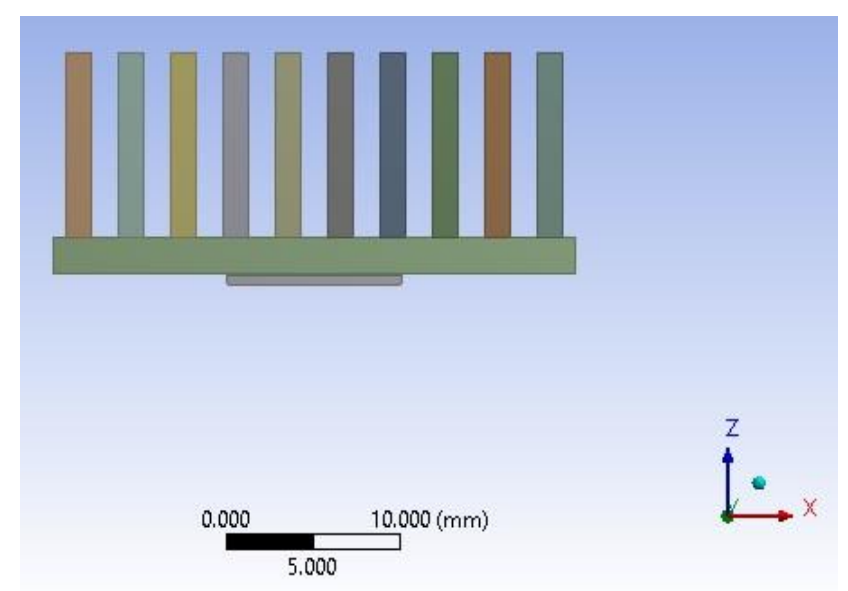

Figure 1: Schematic of a Microelectronic Assembly Package 
Table 1: Microelectronics Assembly Package Factors and its Levels

\begin{tabular}{llll}
\hline Factors & Unit & $\begin{array}{l}\text { Coded } \\
\text { Level Low } \\
(-)\end{array}$ & $\begin{array}{l}\text { Coded } \\
\text { Level } \\
\text { High }(+)\end{array}$ \\
\hline Heat Sink Base Thickness & $\mathrm{mm}$ & 2 & 5 \\
TIM Thickness & $\mathrm{mm}$ & 0.035 & 0.045 \\
Chip Thickness & $\mathrm{mm}$ & 0.5 & 1 \\
\hline
\end{tabular}

Table 2: Central Composite Design without

\begin{tabular}{|c|c|c|c|c|}
\hline \multicolumn{5}{|c|}{ Response Data } \\
\hline Run No. & $\begin{array}{l}\text { Space } \\
\text { Type }\end{array}$ & $\begin{array}{l}\text { Heat Sink } \\
\text { Base } \\
\text { Thickness } \\
(\mathrm{mm})\end{array}$ & $\begin{array}{l}\text { TIM } \\
\text { Thickness } \\
(\mathrm{mm})\end{array}$ & $\begin{array}{l}\text { Chip } \\
\text { Thickness } \\
(\mathrm{mm})\end{array}$ \\
\hline 1 & Factorial & 2 & 0.035 & 0.5 \\
\hline 2 & Axial & 3.5 & 0.04 & 1.104 \\
\hline 3 & Center & 3.5 & 0.04 & 0.75 \\
\hline 4 & Factorial & 5 & 0.035 & 1 \\
\hline 5 & Center & 3.5 & 0.04 & 0.75 \\
\hline 6 & Axial & 3.5 & 0.047 & 0.75 \\
\hline 7 & Factorial & 2 & 0.045 & 1 \\
\hline 8 & Center & 3.5 & 0.04 & 0.75 \\
\hline 9 & Axial & 1.379 & 0.04 & 0.75 \\
\hline 10 & Center & 3.5 & 0.04 & 0.75 \\
\hline 11 & Axial & 3.5 & 0.033 & 0.75 \\
\hline 12 & Center & 3.5 & 0.04 & 0.75 \\
\hline 13 & Axial & 5.621 & 0.04 & 0.75 \\
\hline 14 & Axial & 3.5 & 0.04 & 0.396 \\
\hline 15 & Factorial & 5 & 0.045 & 0.5 \\
\hline
\end{tabular}

\subsection{Load and Boundary Conditions}

This investigation adopted steady state thermal analysis based on the temperature dependent parameters shown in Equation 2.

$$
\frac{d}{d x}\left(K \frac{d T}{d x}\right)+\frac{d}{d y}\left(K \frac{d T}{d y}\right)+\frac{d}{d z}\left(K \frac{d T}{d z}\right)=0
$$

Where $K$ is the thermal conductivity, $\frac{d T}{d x}, \frac{d T}{d y}$, and $\frac{d T}{d z^{\prime}}$ are the temperature gradients. A heat flow of $5 \mathrm{~W}$ was applied to the flip chip, and a natural convection coefficient $\left(5 \mathrm{~W} / \mathrm{m}^{2} \mathrm{~K}\right)$ for stagnant air simplified case was applied on the heat sink. The ambient temperature used for the simulation was $22{ }^{\circ} \mathrm{C}$ and the heat transfer due to radiation was neglected. In this study, it is assumed that heat transfer through conduction starts from the chip through the bonded interface to the heat sink.

\section{RESULTS AND DISCUSSIONS}

The results from this investigation are presented in Sections 3.1-3.7.

\subsection{Mesh Analysis}

The model used in this investigation was adequately meshed with 92334 nodes and 17813 elements. A mesh dependency study was conducted by Ekpu [19]. In the study, it was concluded that a mesh size between $20 \%$ and $40 \%$ of the initial size of a model is ideal for having effective results in simulation work done in ANSYS. It is important to note that the mesh result of the present model adhere to the principle presented in [19]. Figure 2 shows the meshed results used in this investigation.

\subsection{Temperature and Thermal Resistance Analysis}

Temperature output was used as the simulation result because steady state thermal analysis was considered. Figure 3 presents the temperature contour plot of the analysis. By visual inspection of the temperature distribution in Figure 3 , it is observed that temperature contours are concentric in nature. Similar temperature contour plots were recorded in Mendonca et al [20]. This means that the heat generated by the chip is conducted through the bodies in contact to the surroundings. Maximum temperature could be seen around the chip in Figure 3 with a value of $127.96{ }^{\circ} \mathrm{C}$, while the minimum temperature of $126.11^{\circ} \mathrm{C}$ occurred on the heat sink. These temperatures were used to calculate the thermal resistances after a parametric analysis were conducted on the different factors and levels of this study. Thermal resistance is given as:

$$
\begin{aligned}
R & =\frac{\Delta T}{Q} \\
\Delta T & =T_{\text {max }}-T_{\text {min }}
\end{aligned}
$$

Where $Q$ is the heat flow applied, $\Delta T$ is the temperature change in the microelectronics assembly package. The thermal resistance calculated for the different factors and levels were used as the responses of the CCD shown in Table 3.

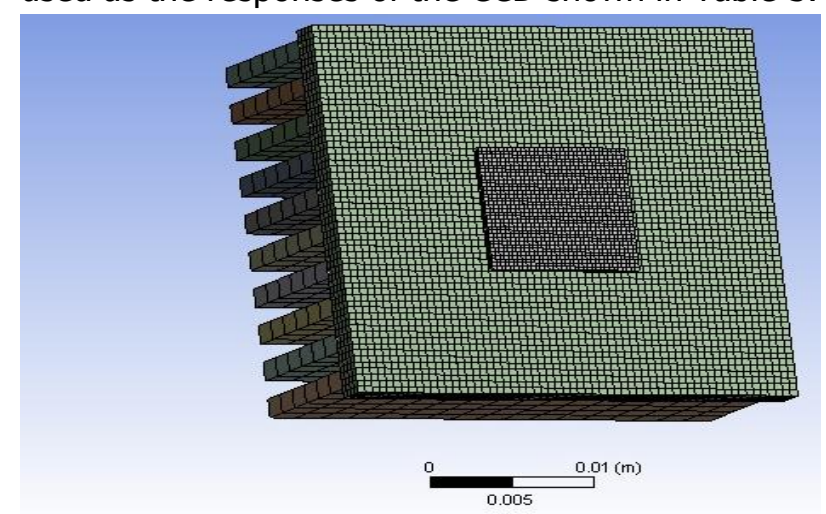

Figure 2: Mesh with 92334 Nodes and 17813 Elements

Vol. 39, No. 4, October 2020 
Table 3: Central Composite Design with Response

\begin{tabular}{lccccc}
\hline Run No. & $\begin{array}{c}\text { Space } \\
\text { Type }\end{array}$ & $\begin{array}{c}\text { Heat Sink Base } \\
\text { Thickness }(\mathrm{mm})\end{array}$ & $\begin{array}{c}\text { TIM Thickness } \\
(\mathrm{mm})\end{array}$ & $\begin{array}{c}\text { Chip Thickness } \\
(\mathrm{mm})\end{array}$ & $\begin{array}{c}\text { Response: Thermal } \\
\text { Resistance }(\mathrm{K} / \mathrm{W})\end{array}$ \\
\hline 1 & Factorial & 2 & 0.035 & 0.5 & 0.37 \\
2 & Axial & 3.5 & 0.04 & 1.104 & 0.328 \\
3 & Center & 3.5 & 0.04 & 0.75 & 0.31 \\
4 & Factorial & 5 & 0.035 & 1 & 0.3 \\
5 & Center & 3.5 & 0.04 & 0.75 & 0.31 \\
6 & Axial & 3.5 & 0.047 & 0.75 & 0.31 \\
7 & Factorial & 2 & 0.045 & 1 & 0.39 \\
8 & Center & 3.5 & 0.04 & 0.75 & 0.31 \\
9 & Axial & 1.379 & 0.04 & 0.75 & 0.448 \\
10 & Center & 3.5 & 0.04 & 0.75 & 0.31 \\
11 & Axial & 3.5 & 0.033 & 0.75 & 0.31 \\
12 & Center & 3.5 & 0.04 & 0.75 & 0.31 \\
13 & Axial & 5.621 & 0.04 & 0.75 & 0.28 \\
14 & Axial & 3.5 & 0.04 & 0.396 & 0.292 \\
15 & Factorial & 5 & 0.045 & 0.5 & 0.274 \\
\hline
\end{tabular}

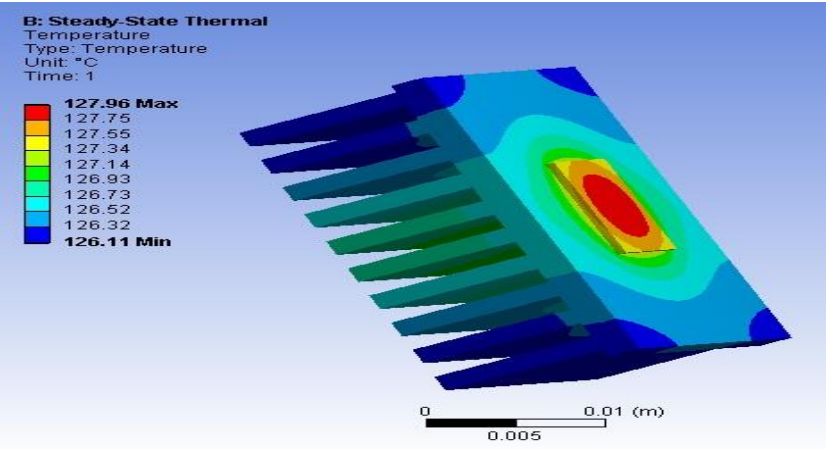

Figure 3: Temperature Distribution Contour Plot

\subsection{Analysis of Variance (ANOVA)}

The main determining factors in ANOVA are the Fvalue and $p$-value. Sada [21], described F-value as the variance of the group means, while $p$-value is the probability of getting a result at the extreme. Table 4 presents the ANOVA analysis for the quadratic model (thermal resistance). As presented in Table 4, the model has an F-value of 895.40, which implies that the model is significant to the study. According to the ANOVA analysis of Design Expert, there is $0.01 \%$ chance that an F-value of 895.40 could happen due to noise. The $p$-values of the model is 0.0001 , meaning it is less than 0.05 thereby indicating that the terms of the model is significant as well. While $p$-values greater than 0.1 are considered not significant. From Table 4, it could be seen that the significant model terms are
$A, C, B C$, and $A^{2}$. Where $A$ is the heat sink base thickness, $C$ is the chip thickness, and $B$ is the TIM thickness.

The goodness of fit statistics validating the thermal resistance response is presented in Table 5. From Table 5, it could be seen that the Predicted $R^{2}$ is $0.9330(93.30 \%)$ and the Adjusted $R^{2}$ is 0.9983 (99.83\%). This demonstrates that over $93.30 \%$ of the total variations in the response model could be explained. The difference between both $\mathrm{R}^{2}$ is about $0.0653(6.53 \%)$ which is less than $0.2(20 \%)$, indicating a reasonable agreement between the Predicted $R^{2}$ and Adjusted $R^{2}$. The signal-to-noise ratio is measured by Adequate (Adeq) Precision. $A$ signal-to-noise ratio higher than 4 is acceptable in most design analysis [21]. In this study, the signalto-noise ratio is 110.19 , which signifies an adequate signal. This means that the model could be used to navigate the design space.

\subsection{Final Equation in Terms of Actual Factors}

The final equation in terms of the actual coded factors for the thermal resistance response is presented in Table 6. From Table 6, it is observed that the equation comprises of individual factors and combined factors. The predictions of the thermal resistances for different given levels of each factor could be estimated by the given equation in Table 6 in terms of the actual factors. 
It is important to note that the equation in Table 6, is not suitable for determining the relative impact of each factor. This is due to the fact that the coefficients were scaled to address the units of each factor and the intercept is not at the centre of the design space.

\subsection{Analysis of Predicted and Actual Responses}

The plot of thermal resistance for the predicted and actual values as against the run order is presented in Figure 4. It is observed from Figure 4 that the trend between the predicted values and the actual values are very closely related. This is as a result of the $6.53 \%$ difference between both Predicted $\mathrm{R}^{2}$ $(93.30 \%)$ and the Adjusted $R^{2}(99.83 \%)$ as discussed in Section 3.3.

In Figure 5, the predicted thermal resistance response is plotted against the actual thermal resistance response. From Figure 5, a linear relationship between the predicted values and actual values could be established. This linear relationship supports the observations from the results discussed in previous sections.

Table 4: ANOVA for Quadratic Model (Thermal Resistance)

\begin{tabular}{cccccc}
\hline Source & Sum of Squares & df & Mean Square & F-value & $p$-value \\
\hline Model & 0.0292 & 9 & 0.0032 & 895.40 & $<0.0001$ \\
significant \\
A-Heat Sink Base Thickness & 0.0141 & 1 & 0.0141 & 3888.00 & $<0.0001$ \\
B-TIM Thickness & 0.0000 & 1 & 0.0000 & 0.0000 & 1.0000 \\
C-Chip Thickness & 0.0006 & 1 & 0.0006 & 178.53 & $<0.0001$ \\
AB & $3.016 \mathrm{E}-06$ & 1 & $3.016 \mathrm{E}-06$ & 0.8308 & 0.4038 \\
AC & $4.500 \mathrm{E}-06$ & 1 & $4.500 \mathrm{E}-06$ & 1.24 & 0.3162 \\
BC & 0.0003 & 1 & 0.0003 & 91.65 & 0.0002 \\
A $^{2}$ & 0.0053 & 1 & 0.0053 & 1447.00 & $<0.0001$ \\
B $^{2}$ & $6.352 \mathrm{E}-06$ & 1 & $6.352 \mathrm{E}-06$ & 1.75 & 0.2431 \\
C $^{2}$ & $6.352 \mathrm{E}-06$ & 1 & $6.352 \mathrm{E}-06$ & 1.75 & 0.2431 \\
Residual & 0.0000 & 5 & $3.630 \mathrm{E}-06$ & & \\
Lack of Fit & 0.0000 & 1 & 0.0000 & & \\
Pure Error & 0.0000 & 4 & 0.0000 & & \\
Cor Total & 0.0293 & 14 & & & \\
\hline
\end{tabular}

Table 5: Goodness of Fit Statistics Validating Response

\begin{tabular}{cccc}
\hline Name & Value & Name & Value \\
\hline Std. Dev. & 0.0019 & $\mathrm{R}^{2}$ & 0.9994 \\
Mean & 0.3235 & Adjusted $\mathrm{R}^{2}$ & 0.9983 \\
C.V. \% & 0.5890 & Predicted R & 0.9330 \\
& & Adeq Precision & 110.1905 \\
\hline
\end{tabular}

Table 6: Final Equation in Terms of Actual Factors

\begin{tabular}{|c|c|}
\hline Coefficient Value & Factors \\
\hline Thermal Resistance & $=$ \\
\hline \multicolumn{2}{|l|}{+0.210641} \\
\hline-0.130324 & *Heat Sink Base Thickness \\
\hline+10.06886 & ${ }^{*}$ TIM Thickness \\
\hline+0.471392 & ${ }^{*}$ Chip Thickness \\
\hline+0.163723 & *Heat Sink Base Thickness * TIM Thickness \\
\hline+0.004000 & ${ }^{*}$ Heat Sink Base Thickness * Chip Thickness \\
\hline-10.31758 & ${ }^{*}$ TIM Thickness * Chip Thickness \\
\hline+0.011597 & ${ }^{*}$ Heat Sink Base Thickness² \\
\hline-36.29630 & ${ }^{*}$ TIM Thickness ${ }^{2}$ \\
\hline-0.014519 & ${ }^{*}$ Chip Thickness ${ }^{2}$ \\
\hline
\end{tabular}




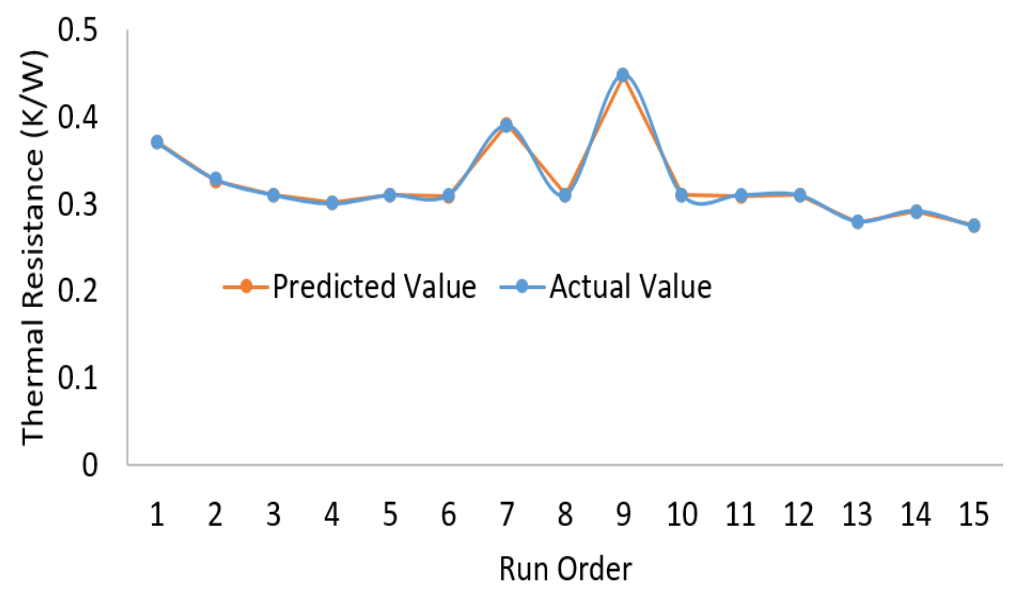

Figure 4: Plot of Thermal Resistance against Simulation Run Order

\section{Design-Expert ${ }^{\circledR}$ Software}

\section{Thermal Resistance}

Color points by value of Thermal Resistance: $0.274 \square 0.448$

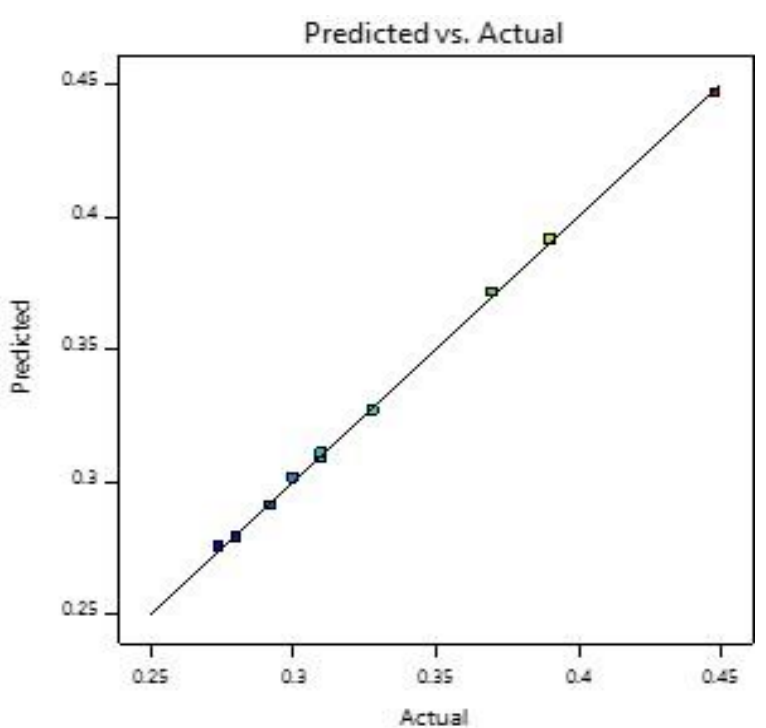

Figure 5: Plot of Predicted vs Actual Thermal Resistance

\subsection{Interactions between Factors in Response Surface Methodology (RSM)}

The interaction between HSB thickness and TIM thickness at chip thickness of $0.75 \mathrm{~mm}$ is presented in Figure 6 . The interaction between both factors showed that the thermal resistance is increased when the HSB thickness reduces and the TIM thickness increases. This may be attributed to the differences between both factors interacting. Therefore, having an optimal value for both factors are desired in reducing the thermal resistance. Note that this interaction is at a constant chip thickness. Figure 7 presents the interaction between HSB thickness and chip thickness at a TIM thickness of $0.04 \mathrm{~mm}$. By visual analysis of Figure 7, it is clearly seen that the thermal resistance is reduced when the chip thickness is low and the HSB thickness is high. Again, this could be attributed to the difference in the thickness of both interacting factors at a constant TIM thickness. Figure 7, also showed that an optimal thermal resistance at 0.04 TIM thickness could be achieved with low chip thickness and high HSB thickness after some trade-off considerations.

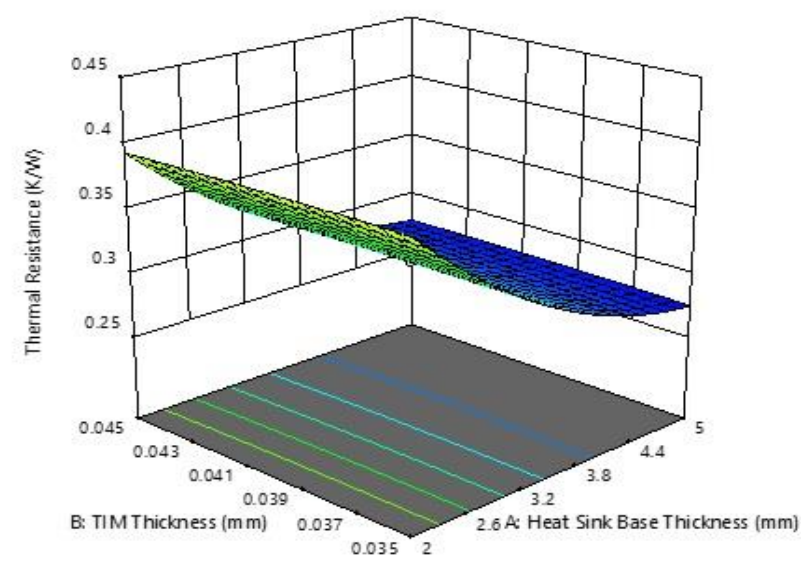

Figure 6: RSM Interaction between HSB Thickness and TIM Thickness 


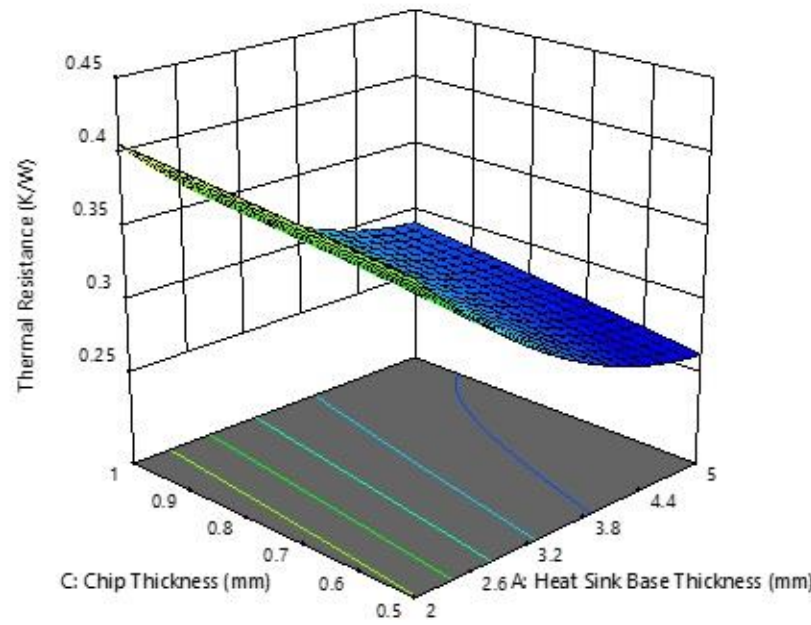

Figure 7: RSM Interaction between HSB Thickness and Chip Thickness

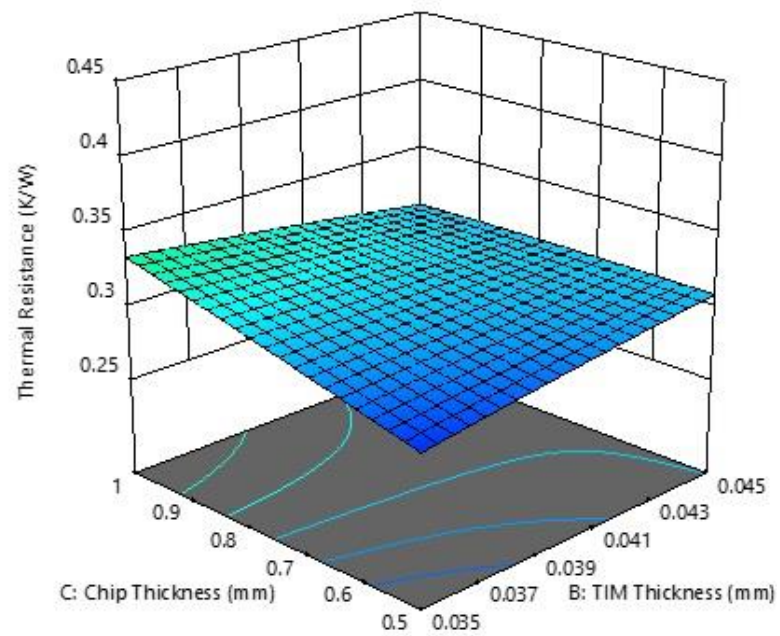

Figure 8: RSM Interaction between TIM Thickness and Chip Thickness

The interaction between TIM thickness and chip thickness at an HSB thickness of $3.5 \mathrm{~mm}$ is presented in Figure 8. It is observed from Figure 8, that the thermal resistance from the interaction of both factors are almost the same. This is expected because of the very small thicknesses of both factors considered. From Figure 8, it is seen that thermal resistance is low when the TIM thickness and chip thickness are low. This signifies that there is an effective heat conduction between TIM thickness and chip thickness based on the results of this investigation.

\subsection{Optimisation Analysis}

This study aimed at having optimal factors that will ensure heat is conducted properly in a microelectronic assembly package, keeping in mind the need to minimise size of the package. From the results discussed in Sections $3.2-3.6$, it is clearly seen that in order to have an optimal setting for this study the thermal resistance will need to be minimised. From the RSM analyses, the optimal coded level for factors used in this study were given as $3.5 \mathrm{~mm}, 0.04 \mathrm{~mm}$, and $0.75 \mathrm{~mm}$ for HSB thickness, TIM thickness, and chip thickness respectively. The optimal mean thermal resistance based on the optimal factors parameter is given as $0.31052 \mathrm{~K} / \mathrm{W}$.

\section{CONCLUSIONS}

The management of heat in microelectronic devices are necessary for the effective function of the devices. However, getting the right balance in microelectronics assembly package remains crucial for the package performance. Hence, this study have proposed an optimal level combination by using RSM based on the three (HSB thickness, TIM thickness, and chip thickness) components studied. The study concludes that $3.5 \mathrm{~mm}, 0.04 \mathrm{~mm}$, and $0.75 \mathrm{~mm}$, for HSB thickness, TIM thickness, and chip thickness respectively will give the optimal mean thermal resistance of $0.31052 \mathrm{~K} / \mathrm{W}$.

\section{REFERENCES}

[1] Kwanda, L.T. "Multi-objective optimization of a rectangular micro-channel heat sink using the augmented $\varepsilon$-constraint method", Engineering Optimization, 2019, DOI: 10.1080/0305215X.2019.1574346

[2] Ekpu, M., Bhatti, R., Ekere, N., Mallik, S., Amalu, E. and Otiaba, K. "Investigation of effects of heat sinks on thermal performance of microelectronic package", 3rd IEEE International Conference on Adaptive Science and Technology (ICAST 2011), Abuja, 2011, pp. 127-132.

[3] Wan, Z. M., Liu, J., Su, K. L., Hu, X. H. and M, S. S. "Flow and Heat Transfer in Porous Micro Heat Sink for Thermal Management of High Power LEDs", Microelectronics Journal, Vol. 42, Number 1, 2011, pp. 632-637.

[4] Dogruoz, M. B. and Arik, M. "On the Conduction and Convection Heat Transfer from Lightweight Advanced Heat Sinks", IEEE Transaction on Components and Packaging Technologies, 2010, pp. 1-8.

[5] Ogunwede, O. I., Abolarin, M. S., Abdulrahman, A.S., Olugboji, O. A., Agboola, J. B., Lawal, S. A. and Isah, L. A. "Process optimization of the mechanical properties of AISI 1020 steel quenched using maize-stover 
ash potash Solution", Nigerian Journal of Technology, 2020, Vol. 39, Number 3, pp. 821 $-829$.

[6] Jagarkal, S. G., Hossain, M. M., Agonafer, D., Lulu, M. and Reh, S. (n.d.). "Design optimization and reliability of PWB level electronic package", The Ninth Intersociety Conference on Thermal and Thermomechanical Phenomena in Electronic Systems, 2004, pp. 368-376

[7] Xu, L., Reinikainen, T., Ren, W., Wang, B. P., Han, Z. and Agonafer, D. "A simulation-based multi-objective design optimization of electronic packages under thermal cycling and bending", Microelectronics Reliability, 2004, vol. 44, Number 12, pp. 1977-1983.

[8] Bailey, C., Tilford, T. and Lu, H. "Reliability Analysis for Power Electronics Modules", 30th International Spring Seminar on Electronics Technology (ISSE), 2007, pp. 12-17.

[9] Oghenejoboh, K. M. "Biosorption of nickel (II) ion from synthetic wastewater on watermelon rind activated carbon using response surface methodology (RSM) optimization approach", Nigerian Journal of Technology, 2018, Vol. 37, Number 3, pp. $647-655$.

[10] Leong, W. C., Abdullah, M. Z. and Khor, C. Y. "Optimization of flexible printed circuit board electronics in the flow environment using response surface methodology", Microelectronics Reliability, 2013, Vol. 53, Number 12, pp. 1996-2004.

[11] Wang, B. P., Han, Z. X., Xu, L. and Reinikainen, T. "A novel response surface method for design optimization of electronic packages", EuroSimE 2005. Proceedings of the 6th International Conference on Thermal, Mechanial and Multi-Physics Simulation and Experiments in Micro-Electronics and MicroSystems, 2005, pp. 175-181.

[12] Gaston, G. J. and Walton, A. J. "The integration of simulation and response surface methodology for the optimization of IC processes", IEEE Transactions on Semiconductor Manufacturing, 1994, Vol. 7, Number 1, pp. 22-33.

[13] Kodiyalam, S., Lin, J. and Wujek, B. "Design of Experiments based response surface models for design optimization", 39th

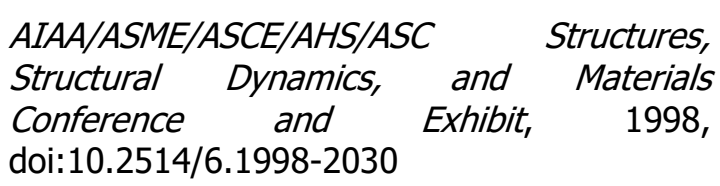

[14] Stoyanov, S. K. (2004). "Optimisation modelling for microelectronics packaging and product design", A PhD Thesis submitted to University of Greenwich London UK, 2004, Last accessed online on $3^{\text {rd }}$ June 2020, https://ethos.bl.uk/OrderDetails.do?uin=uk.bl .ethos.401565

[15] Li, Y., Du, Y., Xu, T., Wu, H., Zhou, X., Ling, $Z$. and Zhang, Z. "Optimization of thermal management system for Li-ion batteries using phase change material", Applied Thermal Engineering, 2018, Vol. 131, pp. 766-778. doi:10.1016/j.applthermaleng.2017.12.055

[16] Montgomery, D. C. "Design and Analysis of Experiments", 7th ed. Asia: John Wiley and Sons, 2009, pp. 388-416.

[17] Ekpu, M., Bhatti, R., Okereke, M. I., Mallik, S. and Otiaba, K. "Fatigue life of lead-free solder thermal interface materials at varying bond line thickness in microelectronics", Microelectronics Reliability, Vol. 54, Number 1, 2014, pp. 239-244.

[18] Ekpu, M., Bhatti, R., Okereke, M. I., Mallik, S. and Otiaba, K. C. "Prediction and optimization of design parameters of microelectronic heat sinks", Journal of Emerging Trends in Engineering and Applied Sciences, Vol. 4, Number 3, 2013, pp. 493-500.

[19] Ekpu, M. "Finite Element Analysis of the Effect of Fin Geometry on Thermal Performance of Heat Sinks in Microelectronics", Journal of Applied Sciences and Environmental Management, Vol. 23, Number 11, 2019, pp. 2059-2063.

[20] Mendonca, R. M., Yalamarty, S. S. and Kini, C. R. "Numerical analysis of heat sinks for led lighting modules", International Journal of Research in Engineering and Technology, Vol. 4, Number 3, 2017, pp. 142-150.

[21] Sada, S. O. "Optimization of weld strength properties of tungsten inert gas Mild steel welds using the response surface methodology", Nigerian Journal of Technology, Vol. 37, Number 2, 2018, pp. 407-415. 